\title{
Author Correction: Misestimation of heritability and prediction accuracy of male-pattern baldness
}

Chloe X. Yap (1) 1, Julia Sidorenko ${ }^{1,2}$, Riccardo E. Marioni ${ }^{3,4}$, Loic Yengo ${ }^{1}$, Naomi R. Wray (1) ${ }^{1,5}$ \&

Peter M. Visscher (1) 1,5

Correction to: Nature Communications; https://doi.org/10.1038/s41467-018-04807-3; published online 29 June 2018

The original version of this Article contained an error in the spelling of the author Julia Sidorenko, which was incorrectly given as Julia Sirodenko. This has now been corrected in both the PDF and HTML versions of the Article. Further, the sixth sentence of the second paragraph of the Correspondence and the legend to Fig. 1 incorrectly omitted citation of work by Heilmann-Helmbach, S. et al. This has now been corrected in both the PDF and HTML versions of the Article.

Heilmann-Helmbach, S. et al. Meta-analysis identifies novel risk loci and yields systematic insights into the biology of male-pattern baldness. Nat. Commun. 8, 14694 (2017).

Published online: 20 November 2018

(i) Open Access This article is licensed under a Creative Commons Attribution 4.0 International License, which permits use, sharing, adaptation, distribution and reproduction in any medium or format, as long as you give appropriate credit to the original author(s) and the source, provide a link to the Creative Commons license, and indicate if changes were made. The images or other third party material in this article are included in the article's Creative Commons license, unless indicated otherwise in a credit line to the material. If material is not included in the article's Creative Commons license and your intended use is not permitted by statutory regulation or exceeds the permitted use, you will need to obtain permission directly from the copyright holder. To view a copy of this license, visit http://creativecommons.org/licenses/by/4.0/.

(C) The Author(s) 2018

\footnotetext{
${ }^{1}$ Institute for Molecular Bioscience, The University of Queensland, Brisbane 4072, Australia. ${ }^{2}$ Estonian Genome Center, Institute of Genomics, University of Tartu, Tartu 51010, Estonia. ${ }^{3}$ Centre for Genomic and Experimental Medicine, Institute of Genetics and Molecular Medicine, University of Edinburgh, Edinburgh EH4 2XU, UK. ${ }^{4}$ Centre for Cognitive Ageing and Cognitive Epidemiology, University of Edinburgh, Edinburgh EH8 9JZ, UK. ${ }^{5}$ Queensland Brain Institute, The University of Queensland, Brisbane 4072, Australia. Correspondence and requests for materials should be addressed to

P.M.V. (email: peter.visscher@uq.edu.au)
} 